\title{
Treatment of non-small cell lung cancer in the era of targeted therapy
}

\author{
James Chung-Man Ho
}

Department of Medicine, The University of Hong Kong, Hong Kong, China; jhocm@hku.hk

Received 2 April 2012; revised 20 May 2012; accepted 8 June 2012

\section{ABSTRACT}

Lung cancer, mostly non-small cell carcinoma (NSCLC), is still a major global problem with devastating outcomes. The majority presents at late stages, in which the chance of cure is minimal. With the better understanding of lung cancer biology, there have been several novel targeted approaches against NSCLC. Anti-angiogenesis has been proven to be an important approach in combination with systemic chemotherapy treatment in NSCLC at the first-line setting. The prototypic monoclonal antibody against vascular endothelial growth factor (VEGF), bevacizumab, is now approved for clinical use in combination with platinum-based chemotherapy in first-line treatment of advanced non-squamous NSCLC, associated with improved response and survival compared with chemotherapy alone. The most notable example of targeted therapy for lung cancer is epidermal growth factor receptor tyrosine kinase inhibitors (EGFR TKI). There have been extensive evidences supporting the superiority of EGFR TKI (like gefitinib or erlotinib) over standard platinum-based doublet chemotherapy in first-line treatment of advanced NSCLC carrying EGFR activating mutations. Almost following the same path as EGFR TKI, a novel target (anaplastic lymphoma kinase, ALK) has been identified recently with a very promising targeted agent (crizotinib) that has already been approved for clinical use in NSCLC carrying ALK rearrangements. Over the past decade, there have been undoubtedly growing armamentaria in the treatment of NSCLC, focusing on personalized and targeted approach.

Keywords: Targeted Therapy; Non-Small Cell Lung Cancer; Bevacizumab; Erlotinib; Gefitinib; Crizotinib

\section{INTRODUCTION}

Lung cancer has remained the top cancer killer worldwide over the past decade, and is expected to be so in the coming years. According to data from World Health Organization, lung cancer accounted for 1.38 million deaths globally in 2008 (http://www.who.int/en/, last accessed on 10 June 2012). The overall prognosis is still poor with an overall 5 -year survival around $15 \%$ only. The majority of lung cancer is histologically non-small cell carcinoma (NSCLC), with increasing predominance of adenocarcinoma. Apart from the lack of effective lung cancer screening in the past, the overall poor prognosis is mainly related to suboptimal treatment outcome for advanced or metastatic disease. With the advances in lung cancer biology, the complicated genetics and molecular pathogenetic pathways of lung cancer have been much better elucidated. In the past decade, there have been major landmark developments in targeted treatment for NSCLC, resulting in major change in the treatment paradigm. The purpose of this short review is to highlight the recent advances in targeted therapy for NSCLC, namely anti-angiogenesis, anti-epidermal growth factor receptor (EGFR) and more recently inhibition of anaplastic lymphoma kinase (ALK).

\section{ANTI-ANGIOGENESIS}

It has been suggested that malignant tumours could not grow beyond $2 \mathrm{~mm}$ in size without efficient blood supply. [1] The occurrence of neovascularization would also enable migration of tumour cells through systemic circulation and subsequent development of distant metastases. In fact, tumours remain dormant and unable to metastasize in the absence of a functional vascular supply. $[2,3]$ The process of angiogenesis is mostly controlled by a balance between proangiogenic and antiangiogenic factors [4]. The most important proangiogenic factor involved in tumour angiogenesis, like in NSCLC, is vascular endothelial growth factor (VEGF) [5]. Common approaches to inhibit VEGF pathway include agents that target VEGF or VEGF receptors. Prototypically, bevacizumab is an anti-VEGF recombinant humanized monoclonal antibody (93\% human immunoglobulin G1 framework and 7\% murine VEGF-binding complementarity- 
determining regions), that prevents VEGF from binding its receptors and thus abrogating downstream biologic activities.

Initial phase II trial of first-line combination of bevacizumab and systemic chemotherapy (carboplatin/paclitaxel) versus chemotherapy alone in advanced NSCLC has demonstrated superior response rate, time to progression and survival in the bevacizumab combination arm, with increased risk of life-threatening haemoptysis in squamous cell carcinoma. [6] Subsequent landmark randomized phase III study (E4599) was conducted comparing the combination of bevacizumab with chemotherapy (carboplatin and paclitaxel) versus chemotherapy alone in the treatment of advanced chemonaive nonsquamous NSCLC. [7] The findings confirmed a statistically significant survival advantage favouring bevacizumab combination arm (median survival 12.3 months vs 10.3 months in bevacizumab/chemotherapy vs chemotherapy alone arms, hazard ratio for death $0.79, \mathrm{p}=$ 0.003 ). The most notable toxicities in bevacizumab/ chemotherapy versus chemotherapy alone arms were grade $3 / 4$ neutropenia $(25.5 \%$ vs $16.8 \%$ ), grade $3 / 4$ hypertension ( $7 \%$ vs $0.7 \%$ ), grade $3 / 4$ proteinuria $(3.1 \%$ vs $0 \%$ ) and grade $3 / 4$ haemorrhage $(4.4 \%$ vs $0.7 \%)$. There were 17 treatment-related deaths ( 15 in bevacizumab/ chemotherapy arm and 2 in chemotherapy alone arm), in which all 5 deaths due to haemoptysis were exclusively from the bevacizumab/chemotherapy arm. This is the first proof-of-principle study to demonstrate superiority in combining targeted therapy with chemotherapy compared to standard chemotherapy alone in the first-line treatment of patients with advanced NSCLC. Following this, the combination of bevacizumab, gemcitabine and cisplatin was also investigated in advanced NSCLC (AVAiL study), with favourable progression-free survival in the bevacizumab/chemotherapy arm compared to chemotherapy alone [8]. The safety of this approach of combining bevacizumab with various first-line systemic chemotherapy regimens has been further confirmed and expanded in phase IV clinical studies to include elderly population and brain metastases [9]. However, there is still a need for reliable predictive biomarkers that may help to identify those who would benefit most.

\section{ANTI-EPIDERMAL GROWTH FACTOR RECEPTOR (EGFR)}

Targeting specific and critical pathways that are essential for the survival of lung cancer can achieve specific tumour cell killing without much bystander damage to normal tissues. The first and well-established example for lung cancer is undoubtedly related to inhibition of EGFR. Functioning as a receptor tyrosine kinase, EGFR orchestrates a series of downstream signaling pathway that regulates tumour cell proliferation, invasion, angio- genesis, metastasis, and apoptosis. Since over-expression of EGFR is commonly found in NSCLC, research has been focused on inhibiting EGFR pathway as an important line of treatment. In general, the approaches to EGFR inhibition can be attained through either monoclonal antibody that targets the extra cellular binding site, or small molecules that target the intracellular adenosine triphosphate (ATP) binding site.

Gefitinib was the first EGFR tyrosine kinase inhibitor (TKI) approved for use in the treatment of advanced NSCLC. Previous large-scale phase III trials (INTACT 1 and 2) failed to demonstrate clinical benefit by combining gefitinib with platinum-based chemotherapy in firstline treatment of advanced NSCLC $[10,11]$. It was approved at the turn of this millennium for second-line treatment of advanced NSCLC mainly based on two phase II trials (IDEAL 1 and 2) of gefitinib monotherapy, without a placebo arm, in previously treated patients with advanced NSCLC [12,13]. The most common adverse effects were skin rash, diarrhea, and rarely interstitial pneumonitis. A subsequent randomized, placebo-controlled, phase III study (ISEL) on gefitinib versus placebo in relapsed advanced NSCLC demonstrated insignificant improvement in survival (median survival $5.6 \mathrm{vs}$ 5.1 months in gefitinib vs placebo), despite some benefit among never smokers and patients of Asian descent [14].

Erlotinib is another EGFR TKI that has also been extensively studied in treatment of NSCLC. Similarly, large-scale phase III trials (TALENT and TRIBUTE) showed no clinical benefit in adding erlotinib to standard platinum-based chemotherapy as first-line treatment of advanced NSCLC. [15] A randomized, placebo-controlled, phase III trial of erlotinib versus placebo in treatment of advanced NSCLC after failure to previous chemotherapy showed superior response rate $(8.9 \%$ vs $1 \%$ ), progression-free survival (2.2 vs 1.8 months) and overall survival (6.7 vs 4.7 months) in favour of erlotinib compared to placebo.[16] The more frequent adverse effects associated with erlotinib treatment were skin rash ( $76 \%$ vs $17 \%$ ), anorexia (69\% vs $56 \%$ ), stomatitis $(19 \%$ vs $3 \%$ ), diarrhoea ( $55 \%$ vs $19 \%)$, ocular toxic effect ( $28 \%$ vs $9 \%$ ) and infection ( $34 \%$ vs $21 \%$ ) compared to placebo.

Based on previous studies of gefitinib and erlotinib in NSCLC, several clinical and molecular predicting factors for response to treatment were widely observed. [17] Activating mutations in the EGFR tyrosine kinase domain (commonly deletion in exon 19 and L858R in exon 21) have been shown to be associated with treatment response, while other mutations (like T790M in exon 20) might predict drug resistance. Interestingly, activating EGFR mutations predictive of EGFR TKI sensitivity are more prevalent in females, Asians, never smokers, and adenocarcinoma. These predictive clinico-epidemiological 
factors have been previously used as the selection criteria for EGFR TKI treatment. The overall picture has become much clearer with the recent reports of several first-line clinical trials of EGFR TKI in NSCLC carrying activating EGFR mutations $[18,19]$. The first landmark phase III clinical trial (IPASS study) was conducted to investigate the role of first-line gefitinib compared with standard chemotherapy (paclitaxel and carboplatin) in an epidemiologically enriched population of advanced NSCLC (adenocarcinoma, neversmokers or former light smokers, Asians) [18]. Importantly, It was found that only around $60 \%$ of tumours carried EGFR mutations in this clinically enriched population. In the subgroup of tumours with activating EGFR mutations, gefitinib demonstrated superior objective response rate $(71.2 \%$ vs $47.3 \%)$ and progression-free survival (hazard ratio $0.48,95 \%$ CI 0.36 0.64) compared with standard chemotherapy. However, gefitinib fared worse in objective response rate $(1.1 \%$ vs $23.5 \%$ ) and progression-free survival (hazard ratio 2.85, 95\% CI 2.05 - 3.98) compared with standard chemotherapy among tumours without EGFR mutations. These findings were subsequently confirmed with a Japanese study comparing first-line gefitinib versus paclitaxel/ carboplatin in advanced adenocarcinoma of lung carrying EGFR mutations[19] and a first-line study comparing erlotinib with standard chemotherapy (gemcitabine and carboplatin) in NSCLC with EGFR mutations (OPTIMA study). [20] Based on these concurring data, it is crucial to have sufficient tumour tissues at diagnosis for molecular (especially EGFR mutation) testing, in order to guide the first-line use of EGFR TKI in advanced NSCLC.

Very recently, a large phase III trial has been conducted to investigate the role of afatinib (a selective irreversible EGFR, ErbB2 and ErbB4 inhibitor) compared with pemetrexed/cisplatin in first-line treatment of EGFR mutated advanced adenocarcinoma of lung (LUX-Lung 3). The just released data (at American Society of Clinical Oncology meeting 2012) have suggested significant improvement in progression-free survival with afatinib compared with chemotherapy arm (median 13.6 vs 6.9 months, HR $=0.47[0.34-0.65] ; \mathrm{p}<0.0001)$ in those carrying common activating mutations.

\section{TARGETING ANAPLASTIC LYMPHOMA KINASE}

Very much analogous to the development of EGFR targeting approach, it has been recently discovered that a novel oncogene (anaplastic lymphoma kinase (ALK) rearrangements, commonly EML4-ALK fusion) could be accountable for lung carcinogenesis in around 5\%. [21] Interestingly, the occurrence of ALK rearrangements shares the same epidemiological or clinical preponderance as in EGFR mutations (i.e. nevermokers, adenocar- cinoma), but tends to be exclusively found in EGFR wild-type (i.e. lack of mutations). A recent phase I study has provided very promising evidence that a specific ALK inhibitor (crizotinib) could result in significant tumour response among those NSCLC carrying the ALK rearrangements. [22] This has led to the expedited approval by US Food and Drug Administration in treatment of NSCLC with ALK rearrangements. Ongoing phase II and III clinical trials on crizotinib are underway to establish its role in management of this subgroup of NSCLC.

\section{CONCLUSIONS}

The era of targeted approach in management of advanced NSCLC has certainly begun over the past few years and the field is expected to be evolving rapidly in the near future. Lung cancer is no longer considered a homogeneous disease. Despite traditional classification based on histology, there is increasing clinical demand of tumour molecular profiling to allow logical choice of specific targeted treatment. Second-generation targeted agents and multi-targeted agents are currently tested in clinical trials, which will help to expand the existing armamentaria in the battle against lung cancer.

\section{REFERENCES}

[1] Folkman, J. (1990) What is the evidence that tumors are angiogenesis dependent? Journal of the National Cancer Institute, 82, 4-6. doi:10.1093/jnci/82.1.4

[2] Folkman, J. (1971) Tumor angiogenesis: Therapeutic implications. New England Journal of Medicine, 285, 11821186. doi:10.1056/NEJM197111182852108

[3] Folkman, J. (1990) Endothelial cells and angiogenic growth factors in cancer growth and metastasis. Introduction. Cancer and Metastasis Reviews, 9, 171-174. doi:10.1007/BF00046358

[4] Takeda, A., Stoeltzing, O., Ahmad, S.A., Reinmuth, N., Liu, W., Parikh, A., Fan, F., Akagi, M. and Ellis, L.M. (2002) Role of angiogenesis in the development and growth of liver metastasis. Annals of Surgical Oncology, 9, 610-616. doi:10.1007/BF02574475

[5] Hicklin, D.J. and Ellis, L.M. (2005) Role of the vascular endothelial growth factor pathway in tumor growth and angiogenesis. Journal of Clinical Oncology, 23, 10111027. doi:10.1200/JCO.2005.06.081

[6] Johnson, D.H., Fehrenbacher, L., Novotny, W.F., Herbst, R.S., Nemunaitis, J.J., Jablons, D.M., Langer, C.J., DeVore, R.F. III, Gaudreault, J., Damico, L.A., Holmgren, E. and Kabbinavar, F. (2004) Randomized phase II trial comparing bevacizumab plus carboplatin and paclitaxel with carboplatin and paclitaxel alone in previously untreated locally advanced or metastatic non-small-cell lung cancer. Journal of Clinical Oncology, 22, 2184-2191. doi:10.1200/JCO.2004.11.022

[7] Sandler, A., Gray, R., Perry, M.C., Brahmer, J., Schiller, J.H., Dowlati, A., Lilenbaum, R. and Johnson, D.H. (2006) 
Paclitaxel-carboplatin alone or with bevacizumab for non-small-cell lung cancer. New England Journal of Medicine, 355, 2542-2550. doi:10.1056/NEJMoa061884

[8] Reck, M., Von Pawel, J., Zatloukal, P., Ramlau, R., Gorbounova, V., Hirsh, V., Leighl, N., Mezger, J., Archer, V., Moore, N. and Manegold, C. (2009) Phase III trial of cisplatin plus gemcitabine with either placebo or bevacizumab as first-line therapy for nonsquamous non-small-cell lung cancer: AVAiL. Journal of Clinical Oncology, 27, 1227-1234. doi:10.1200/JCO.2007.14.5466

[9] Dansin, E., Cinieri, S., Garrido, P., Griesinger, F., Isla, D., Koehler, M. and Kohlhaeufl, M.(2012) MO19390 (SAiL): Bleeding events in a phase IV study of first-line bevacizumab with chemotherapy in patients with advanced non-squamous NSCLC. Lung Cancer, 76, 373-379. doi:10.1016/j.lungcan.2011.11.020

[10] Giaccone, G., Herbst, R.S., Manegold, C., Scagliotti, G., Rosell, R., Miller, V., Natale, R.B., Schiller, J.H., Von Pawel, J., Pluzanska, A., Gatzemeier, U., Grous, J., Ochs, J.S., Averbuch, S.D., Wolf, M.K., Rennie, P., Fandi, A. and Johnson, D.H. (2004) Gefitinib in combination with gemcitabine and cisplatin in advanced non-small-cell lung cancer: A phase III trial-INTACT 1. Journal of Clinical Oncology, 22, 777-784. doi:10.1200/JCO.2004.08.001

[11] Herbst, R.S., Giaccone, G., Schiller, J.H., Natale, R.B., Miller, V., Manegold, C., Scagliotti, G., Rosell, R., Oliff, I., Reeves, J.A., Wolf, M.K., Krebs, A.D., Averbuch, S.D., Ochs, J.S., Grous, J., Fandi, A. and Johnson, D.H. (2004) Gefitinib in combination with paclitaxel and carboplatin in advanced non-small-cell lung cancer: A phase III trial-INTACT 2. Journal of Clinical Oncology, 22, 785794. doi:10.1200/JCO.2004.07.215

[12] Kris, M.G., Natale, R.B., Herbst, R.S., Lynch, T.J. Jr., Prager, D., Belani, C.P., Schiller, J.H., Kelly, K., Spiridonidis, H., Sandler, A., Albain, K.S., Cella, D., Wolf, M.K., Averbuch, S.D., Ochs, J.J. and Kay, A.C. (2003) Efficacy of gefitinib, an inhibitor of the epidermal growth factor receptor tyrosine kinase, in symptomatic patients with non-small cell lung cancer: A randomized trial. JAMA, 290, 2149-2158. doi:10.1001/jama.290.16.2149

[13] Fukuoka, M., Yano, S., Giaccone, G., Tamura, T., Nakagawa, K., Douillard, J.Y., Nishiwaki, Y., Vansteenkiste, J., Kudoh, S., Rischin, D., Eek, R., Horai, T., Noda, K., Takata, I., Smit, E., Averbuch, S., Macleod, A., Feyereislova, A., Dong, R.P. and Baselga, J. (2003) Multi-institutional randomized phase II trial of gefitinib for previously treated patients with advanced non-small-cell lung cancer (The IDEAL 1 Trial). Journal of Clinical Oncology, 21, 2237-2246. doi:10.1200/JCO.2003.10.038

[14] Thatcher, N., Chang, A., Parikh, P., Rodrigues, P.J., Ciuleanu, T., Von Pawel J., Thongprasert, S., Tan, E.H., Pemberton, K., Archer, V. and Carroll, K. (2005) Gefitinib plus best supportive care in previously treated patients with refractory advanced non-small-cell lung cancer: Results from a randomised, placebo-controlled, multicentre study (Iressa Survival Evaluation in Lung Cancer). Lancet, 366, 1527-1537. doi:10.1016/S0140-6736(05)67625-8

[15] Perez-Soler, R. (2004) The role of erlotinib (Tarceva, OSI $774)$ in the treatment of non-small cell lung cancer. Clini- cal Cancer Research, 10, 4238s-4240s. doi:10.1158/1078-0432.CCR-040017

[16] Shepherd, F.A., Rodrigues, P.J., Ciuleanu, T., Tan, E.H., Hirsh, V., Thongprasert, S., Campos, D., Maoleekoonpiroj, S., Smylie, M., Martins, R., Van Kooten, M., Dediu, M., Findlay, B., Tu, D., Johnston, D., Bezjak, A., Clark, G., Santabarbara, P. and Seymour, L. (2005) Erlotinib in previously treated non-small-cell lung cancer. New England Journal of Medicine, 353, 123-132.

doi:10.1056/NEJMoa050753

[17] Calvo, E. and Baselga, J. (2006) Ethnic differences in response to epidermal growth factor receptor tyrosine kinase inhibitors. Journal of Clinical Oncology, 24, 21582163. doi:10.1200/JCO.2006.06.5961

[18] Mok, T.S., Wu, Y.L., Thongprasert, S., Yang, C.H., Chu, D.T., Saijo, N., Sunpaweravong, P., Han, B., Margono, B., Ichinose, Y., Nishiwaki, Y., Ohe, Y., Yang, J.J., Chewaskulyong, B., Jiang, H., Duffield, E.L., Watkins, C.L., Armour, A.A. and Fukuoka, M. (2009) Gefitinib or carboplatin-paclitaxel in pulmonary adenocarcinoma. New England Journal of Medicine, 361, 947-957. doi:10.1056/NEJMoa0810699

[19] Maemondo, M., Inoue, A., Kobayashi, K., Sugawara, S., Oizumi, S., Isobe, H., Gemma, A., Harada, M., Yoshizawa, H., Kinoshita, I., Fujita, Y., Okinaga, S., Hirano, H., Yoshimori, K., Harada, T., Ogura, T., Ando, M., Miyazawa, H., Tanaka, T., Saijo, Y., Hagiwara, K., Morita, S., Nukiwa, T. and North-East Japan Study Group (2010) Gefitinib or chemotherapy for non-small-cell lung cancer with mutated EGFR. New England Journal of Medicine, 362, 2380-2388. doi:10.1056/NEJMoa0909530

[20] Zhou, C., Wu, Y.L., Chen, G., Feng, J., Liu, X.Q., Wang, C., Zhang, S., Wang, J., Zhou, S., Ren, S., Lu, S., Zhang, L., Hu, C., Hu, C., Luo, Y., Chen, L., Ye, M., Huang, J., Zhi, X., Zhang, Y., Xiu, Q., Ma, J., Zhang, L. and You, C. (2011) Erlotinib versus chemotherapy as first-line treatment for patients with advanced EGFR mutation-positive non-small-cell lung cancer (OPTIMAL, CTONG-0802): A multicentre, open-label, randomised, phase 3 study. Lancet Oncology, 12, 735-742. doi:10.1016/S1470-2045(11)70184-X

[21] Soda, M., Choi, Y.L., Enomoto, M., Takada, S., Yamashita, Y., Ishikawa, S., Fujiwara, S., Watanabe, H., Kurashina, K., Hatanaka, H., Bando, M., Ohno, S., Ishikawa, Y., Aburatani, H., Niki, T., Sohara, Y., Sugiyama, Y. and Mano, H. (2007) Identification of the transforming EML4-ALK fusion gene in non-small-cell lung cancer. Nature, 448, 561-566. doi:10.1038/nature05945

[22] Kwak, E.L., Bang, Y.J., Camidge, D.R., Shaw, A.T., Solomon, B., Maki, R.G., Ou, S.H., Dezube, B.J., Jänne, P.A., Costa, D.B., Varella-Garcia, M., Kim, W.H., Lynch, T.J., Fidias, P., Stubbs, H., Engelman, J.A., Sequist, L.V., Tan, W., Gandhi, L., Mino-Kenudson, M., Wei, G.C., Shreeve, S.M., Ratain, M.J., Settleman, J., Christensen, J.G., Haber, D.A., Wilner, K., Salgia, R., Shapiro, G.I., Clark, J.W. and Iafrate, A.J. (2010) Anaplastic lymphoma kinase inhibition in non-small-cell lung cancer. New England Journal of Medicine, 363, 1693-1703. doi:10.1056/NEJMoa1006448 